\title{
Impact of Crude Prices on Retail Prices - A Time Series Analysis
}

\author{
Neelu Tiwari
}

\begin{abstract}
The UK has emerged as one of the largest producers of petroleum in the world. A significant amount of petroleum is used for fulfilling the energy demand within the country. However, the country witnessed a different trend from 2015. This is mainly due to the increase in imports of petroleum in order to meet domestic needs. To this, there is a need to identify the impact of changes exist in petrol and crude oil prices in the $U K$. In this context, the researcher has undertaken primary research to derive conclusions which are case specific and can comply with the research aim.
\end{abstract}

The study used secondary data for the year 2015-2018 and conducted multivariate time series analysis. A series of tests including unit root, ARIMA, and co-integration tests were used to derive the results. The study found that there was an asymmetric relationship between the movements of prices of crude oil with respect to retail fuel prices in the long run. However, the study is not without limitations which are represented at the end of the study following with its future scope.

Index Terms: Autoregressive, Co-integration, Crude Prices, Regression, Stationarity, Unit root,

\section{INTRODUCTION}

During the 1980s, the market conditions entailed free movement of crude oil prices (Gienko, 2009). There was an unequal increase or decrease between the wholesale and retail fuel prices both in short span of time as well as overtime (Noel, David, \& Cassie, 2016; Sabnavis, Jagasheth, Khutal, \& Kaushik, 2017). In this regard, the occurrences of unfair fuel prices were much raised as to the steep changes in fuel prices. The working of the fuel market turned to be major attention among many economists since it leads to a loss for many in its supply chain including consumers(Atil, Lahiani, \& Khuong Nguyen, 2014). In this context, the present study has concentrated its scope on the petroleum industry of the UK. Although the share of UK to the global supply of petroleum is only $1.1 \%$, this naturally sourced product plays a pivotal role in quenching the energy needs of the country (Oil \& Gas UK, 2018). The UK is ranked15th among two hundred countries in terms of consumption of petroleum. IN 2015 particularly the quantity of around 15.45 barrels of petroleum was consumed (Brinkhoff, 2018). After 1998, the consumers felt the need to replace the non-renewable sources of energy. Most of the consumers started adopted renewable

\section{Revised Manuscript Received on July 5, 2019}

Neelu Tiwari , Management, AKTU/ Jaipuria Institute of Management, Ghaziabad, India. sources of energy. (Monthly Business Survey, 2016) According to (Statista, 2017), in the UK, this eventually led to falling in the normal intake of petrol and its products from

1998 to 2016 with the value being around 70 million metric tons.

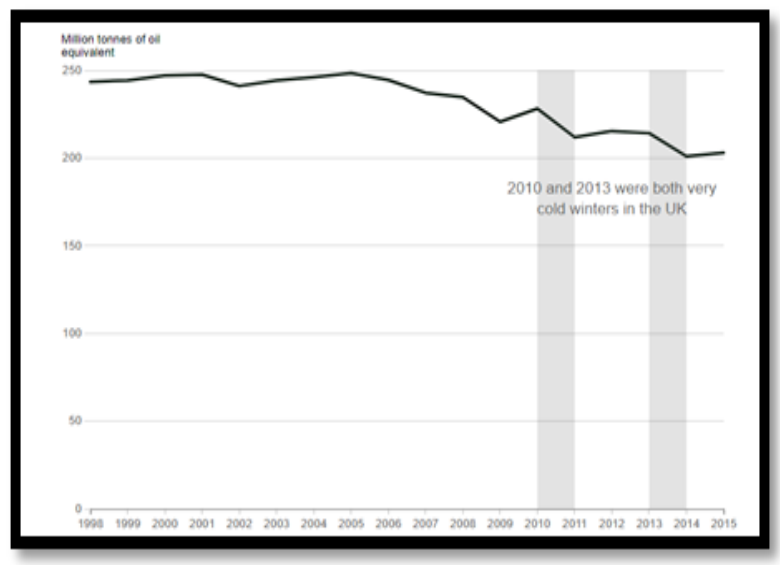

Figure 1

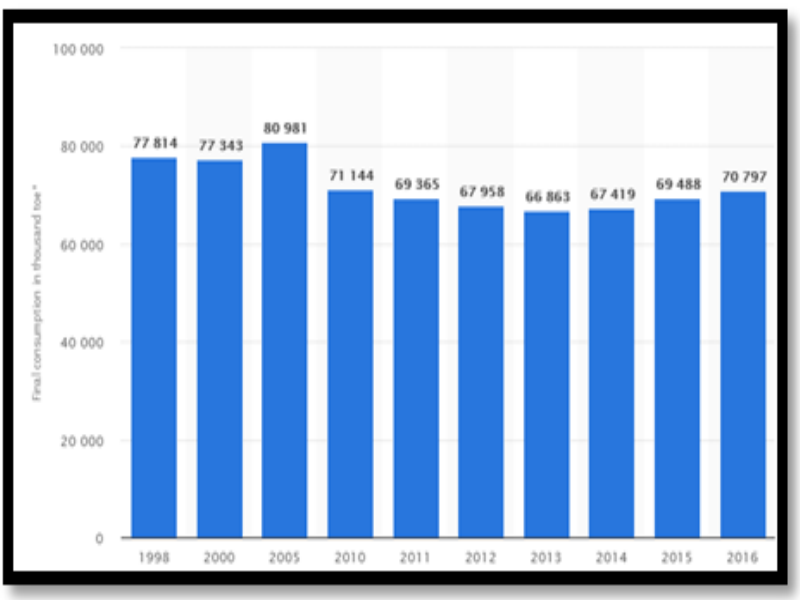

Figure 2

Figure 1 and Figure 2: Energy Consumption in UK (1998-2015), Source: (Business Survey, 2016)

The depressing agenda to this booming industry was much viewed after 2015 as the country turned out to be largely dependent on its imports which are required to meet the domestic needs (Bacon, 1986).

\section{Published By:}

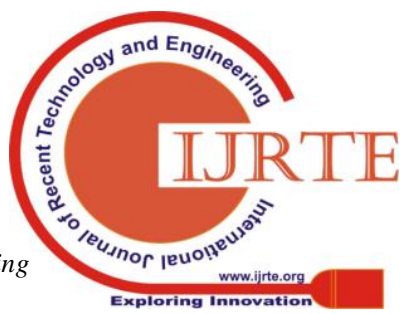


The country was largely dependent on petroleum imports from the around the United Kingdom Continental Shelf in the North Sea area. However, it is further expected that the country will face further negative growth in the same from 2019-2035 due to fall in existing reserves of non-renewable energy and a rapid decrease in the production at the domestic level (Statista, 2018).

There are many factors that impact the fuel prices in the UK for example taxes, government duty and retailer' cost-profit ratio of wholesaler and cost of producing petroleum products in the open market (Bacon, 1986; Cook, 2004; Deng, Jiang, \& Sun, 2018). In addition to this, the predominant exchange rate, domestic competition, commercial objectives of the operators and seasonality affect the petroleum prices. (Monthly Business Survey, 2016).Apart from these factors, Brent Crude serves as the major benchmark in assessing petroleum prices in the UK(UKPIA, 2017). Also, the refinery margin that adds to the profitability within the petroleum market is seen to be low in the case of the UK until 2014 (Ibrahim, 2017). In regards to Northwest Europe, this can be explained through fall in the refinery margin with respect to cracking of Brent. It was estimated in 2012 that the margin was around $3.3 \mathrm{US} /$ barrel which fell to 0.52 US \$ per barrel in the first quarter of 2013. However, this trend changed to rise from 2014 as the country witnessed a gradual increase in the refinery margin from 0.52 US \$ per barrel in 2013 to 1.77 \$ US per barrel during 2014(Statista, 2018).

Following this, it was analyzed that shortage of domestic supply, over-dependence on import and rising taxes impacted the petroleum prices in the UK hugely. In fact, fuel duty rose to $£ 35$ billion by the end of 2017 inclusive of the Value Added Tax (Waghmare, 2018).

In consideration of the background of fuel pricing in the $\mathrm{UK}$, the economic theory in relation to price adjustments has been taken into consideration subsequently. Specifically, the speed of price adjustment is dependent on the market structure such that the impact of exogenous variables on the dependent variable is analyzed within an average length of time periods(Lanza, 1991). As per many statisticians, there exists a relationship between the structure of the market and determining the final fuel price(Frey \& Manera, 2007). Also, the theory of price indicates the allocation of resources and mixed output appropriately(Arrow, 1959). Further another theory that is the cost-based pricing theory asserts that input costing is vital in making decisions(Helm, 2012). Suppose the input price is constant then the output is constant too. These theories with respect to asymmetric price transmission (APT) is consequently another name to "rockets and feathers". The price modifications at either side of the supply chain do not appear on its contrary side in addition to noteworthy delay (Dias, Marques, Martins, \& Silva, 2009). In addition, the equilibrium theory encompassing the relationship between demand-supply and pricing platform in developing an overall equilibrium with respect to various conditions is analyzed. There were majorly three parameters identified in regards to asymmetric price changes(Meyer \& Von Cramon-Taubadel, 2002). First change accounted on the speed of price adjustments, second identifies the positive or negative nature of APT and the third model is spatial or vertical. Further, other factors which are responsible for APT comprise of the pricing power and the adjustment costs. In addition, the other variables responsible for APT includes market power and adjustment costs. The market power captures factors covering non- competitive structure of the market. This behavior is shown by the middle man in order to squeeze the market. However, the adjustment costs capture all the price changes included within the topmost and bottom nodes of the supply chain process (Noel et al., 2016). Such adjustment costs refer to the changes in measures of the price at the upper and lower end of the supply chain. Further, various other reasons that are responsible for the asymmetric price transmission include the intervention of the government, balance within demand/supply, support price and geopolitical reasons (Zakaria \& Zakaria, 2008).

In order to represent the transmission model, it is important to understand the uses of different models. Among all the models, piecewise linear and regime-dependent co-integration economic methods are widely used. Further, the error correction model is a technique that uses local polynomial for estimating non-parametrical values (Lütkepohl, 2005). This model is a type of multi-time series model that is mainly utilized for its data. The underlying variables within the model are followed by a long probabilistic trend, widely known as co-integration. This model is widely criticized on the basis of unrealistic assumptions that arise in the functional form and is based upon the nature of transition (Kanioura \& Turner, 2003). The threshold vector correction model eliminates this problem and is utilized hugely within the price change process amidst unexpected rate variations. This is a flexible technique which does not offer any price change prices eventually. This method enables flexibility in its approach and often don't allow major changes in the price transmission process. Apart from this, there are several other regime dependent integration methods, that can be used for making the dealings parameterized(Cottrell, 2004; Rosales \& Von-Cramon, 2014).

\section{NEED OF THE STUDY}

Undergoing the background on price transmission theory in relation to the influence of fluctuations in petrol and crude oil prices, there is very less empirical work undertaken by economists. It is of utmost importance to analyze this agenda with respect to the UK to draw out general conclusions and not case specific. There are various petroleum products that are manufactured in the UK. These products fulfill the demand of the modern society by providing the energy required by the power industry, the fuel needed by the transport systems and the raw material put into the supply chains involving the production of numerous kinds of indispensable products (Oil

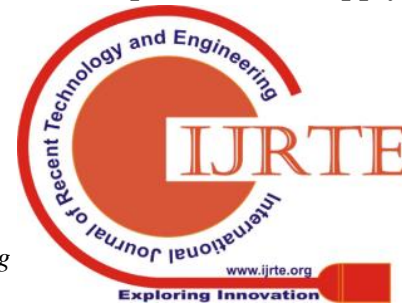


\& Gas UK, 2018). Also, the petroleum products in the UK meets $75 \%$ energy requirements of the country and this is an essential subject to be discussed meticulously (Statista, 2018).

Hence the study is essential for practitioners within the business in order to analyze how a country's retail prices are impacted by the changes caused at a global level. Further, how these changes affect future trends.

\section{AIM AND OBJECTIVES}

In light of the above-mentioned knowledge on price adjustment within the petroleum market, the aim of the study is to examine the symmetric or asymmetric association between retail petrol price and world crude prices.

Perennial to this aim the study has the following two objectives:

1. Analyzing the empirical substantiation on the symmetry concerning retail petrol price and the global crude price of a country.

2. To assess the impact of crude prices movement on retail petrol price movements in the UK.

\section{LITERATURE REVIEW}

The researchers are much intrigued in investing the after effects of volatility and shocks in prices. However, there has been little evidence found on the work done to view the impact of price adjustment in a short or long period of time in a region.

In this regard, the study of Lanza, (1991)viewed insight on price changes within the German gasoline market during 1980-90. There were two models developed- one at the refinery stage and the second at the customer or pump level. This study concluded that if there is a price rise or drop at the refinery stage, there is a weak price adjustment as well as asymmetry. In addition to this, at the customer level, the speed of adjustment is lower in the case of retail distributors. Frey and Manera, (2007)presented a methodology of meta-analysis in addition to a wide empirical reviewed literature. The study discovered that there are some new variables that can be used to analyze the price symmetry within the market. These variables are characterized in terms of long run and short run, effects due to lag, the time needed for the reaction, equilibrium adjustment and many more. The results of the study indicate that asymmetry can occur within different price distribution and across various economic models.

The study of (Karagiannis, Panagopoulos, \& Vlamis, 2015) compiled research covering an equal or similar movement of prices in the EU. In this study, the market of gasoline of France, Spain, Germany, and Italy was examined with respect to price adjustments. This study calculated symmetrical adjustment in prices for long and short term period. This analysis was done using an error correction model that investigated price and hypothesis testing. The study resulted in symmetric upward and downward movement of prices across the four economies undertaken.

Zlatcu, Kubinschi, and Barnea, (2015) in their study investigated the relationship between crude and retail prices with respect to its volatility. In this study, there were five economies undertaken for examining the change in the fuel prices within six years (2008 to 2014). These included Romanian, Poland, Germany, France and the Czech Republic. This particular study conducted both univariate and multivariate GARCH testing models. The study depicted that volatility in prices turned to be highest during the financial crisis. Also, the correlation for the given time series was asymmetric which was further verified under integration analysis.

Perdiguero-García, (2013)asserted the potential existence of asymmetries in the international gasoline market. This paper revolves around energy economics literature including a meta-analysis approach for analyzing industry segment, quantity, and quality data. However, this study was a poor amalgamation of theoretical and methodology applied in order to derive the answers.

Kristoufek and Lunackova, (2014) in their study propounded on feather and rocket connotations among the prices of retail gasoline and crude oil. Likewise, the study entailed an error correction model that captured on to the return of prices to equilibrium at a slower rate than expected. This is what is known as the "Joseph effect". Seven economies were accounted with their data for assessing asymmetry in price adjustment. A wave test, median test, and rescaled range ratio test was conducted to derive the results. Finally, the study concluded that no nation has asymmetry in price adjustment of crude oil and gasoline.

Silva et al., (2014)addresses changes in gasoline price transmission in the Brazilian market. This study, unlike the other studies, used disaggregated data from different regions during 2004-2011. Also, this study resulted in symmetric transmission in retail price within the gasoline market. AtiL, Lahiani, and Khuong Nguyen, (2014) discussed on asymmetric price distribution using the model of non-linear autoregressive distributed lags i.e. NARDL. It is a new type of model which examines the variation of the crude oil prices in retail gasoline and natural gas prices too. This paper covered nonlinearities within the short and long run via the means of negative and positive partial sum decompositions for a certain set of variables which are already determined. The study showed that there was again an asymmetric and nonlinear movement of prices in the short run. Nevertheless, equivalent dissemination in the movement of price was eminent within the long span of time.

\section{CONCEPTUAL FRAMEWORK}

After reviewing the literature on the relationship between the movement of price between retail petrol and crude oil, the following model is developed to attain the aim of the study. This study used premium unleaded in place of the retail prices in the UK as its representative. However, the independent variable for the study is global crude oil price.

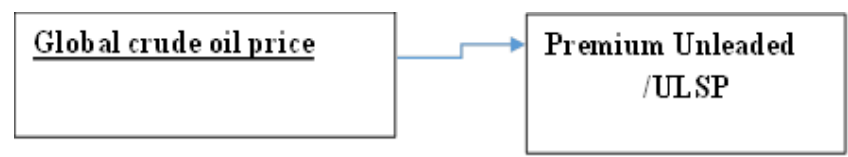

Figure 2: Conceptual framework 


\section{HYPOTHESIS FORMULATION}

Following hypothesis is developed in line to the aim of the study.

Null Hypothesis: There is an asymmetric association between the movement of retail petrol prices and the movement of crude oil prices.

Alternate Hypothesis: There is an asymmetric association between the movement of retail petrol prices and the movement of crude oil prices.

\section{RESEARCH METHODOLOGY}

A research methodology represents a theoretical framework discussing the tools and techniques undertaken to address the main problem of the study and attain its aim (Shah \& Al-Bargi, 2016).

A descriptive and explanatory approach was followed in congruence to the objectives defined. The descriptive approach aided in determining the asymmetrical/symmetrical relationship within the retail petrol and crude oil prices while the explanatory approach identified the robustness of this relationship statistically for the years ahead. A deductive approach underlying the quantitative research design was used to attain results for the framed hypothesis.

For the present study, a multivariate time series quantitative data was used that in turn was gathered from secondary sources for the year 2015-2018. The data has been collected from the Department for Business, Energy and Industrial Strategy. Further, this data was analyzed using unit root testing, ARIMA modeling and testing for co-integration. These techniques assisted the researcher in predicting and analyzing the time series data. The software used by the researcher for deriving results using collected data in STATA.

\section{DATA ANALYSIS AND INTERPRETATION}

The present study aims to examine the impact of retail petrol price movements in crude price movement. Perennial to this aim the researcher used multivariate monthly time series data for the time period 2015 to 2018. For the current study, the independent variable is the price of crude oil whereas the dependent variable is the premium unleaded/ULSP.

Following the sequence of steps were conducted in determining the relationship between variables.

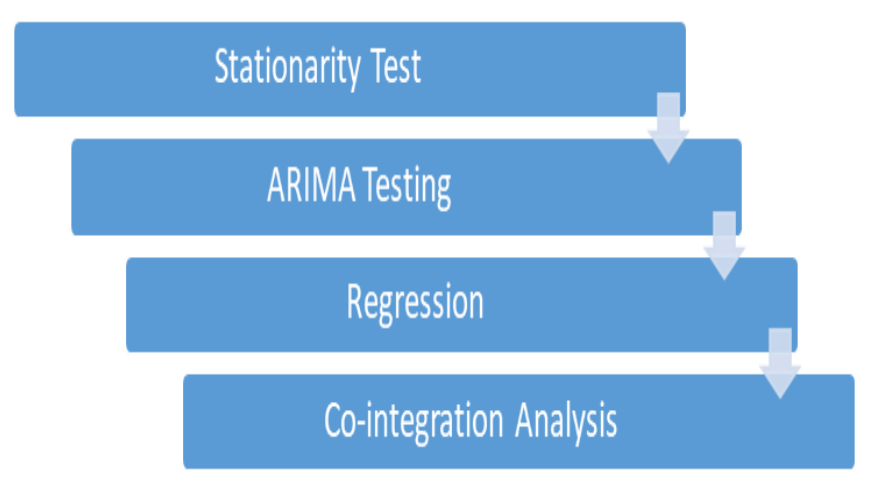

Figure 3: Tests undertaken for the study

\section{STATIONARITY TEST (UNIT ROOT TEST)}

The trend of the given time series is viewed in the diagram below. It can be viewed that there were no unique peaks or any variations for premium unleaded whereas there is a sharp decline in the price of crude oil in January 2016 and at the end of the year 2018. However, the series is continually rising for the price of crude oil. Further, this price is forecasted to rise in 2019.

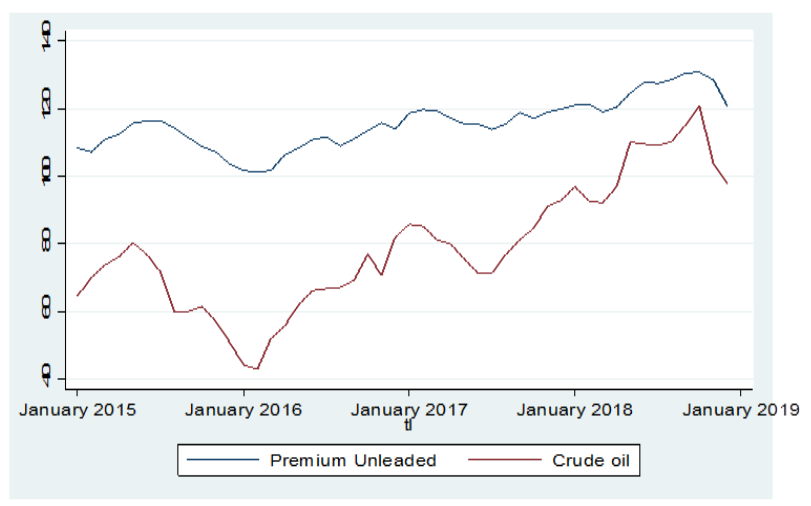

Figure 4: Time series Plot

The prior step is to identify if the given time series is stationary or not i.e. there must not be any unit root in the series. This indicates that the mean, variance and autocorrelation is constant over time (Zivot \& Wang, 2006). Hence for checking stationarity, the following hypothesis is tested using an augmented dickey fuller test.

HO: The given time series is not stationary.

H1: The given time series is stationary.

The criterion to test stationarity is evaluated from the test statistic being significant at $\mathrm{p}<0.05$. In addition, the critical values are greater than the test statistic then the null hypothesis can't be rejected indicating the existence of unit root. Hence the results in the appendix from table 1, clearly indicate that there is a unit root and thus the time series is not stationary.

\section{ARIMA TESTING}

This testing includes autoregressive (AR), integrated (I) and moving average (MA) detection in the given time series data in order to make the series stationary. These tests are denoted as (p, d, q) respectively. The values for p,d, q as $0,1,2 \ldots$ depicts that

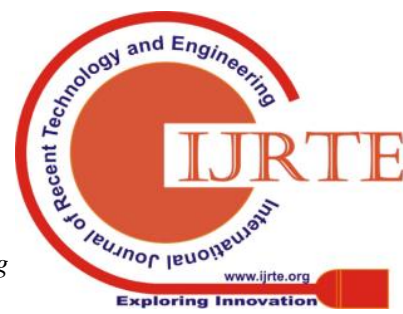


model incorporated corresponding lags and differences (Agrawal, 2011). AR model undertakes the impact of variables on its own lagged values. To detect the relationship between the observation and its residual error, Moving Average Model (MA) is used. Lastly, integrated (I) testing investigates the impact of differences of given observations from its previous values on the performance of the given time series data.

Primarily the series were undertaken for differencing where d_premiumunleaded was generated from premium unleaded (Premium Unleaded) and _crudeoil was generated from crude oil(Crude Oil). Now, these series were again checked for stationarity using the dickey fuller test.

Table 2 in appendix specifies there are significant results since the trace statistic is significant in both of the cases and greater than the critical values.

Hence, it can be said that the variables have turned out to be stationary which in turn indicates that there exists no root in both the series. In addition to this, the graph shown below represents the differentiated variables. The graph clearly indicates that there is no trend among the variables. Thus detrending has been done through differentiating.

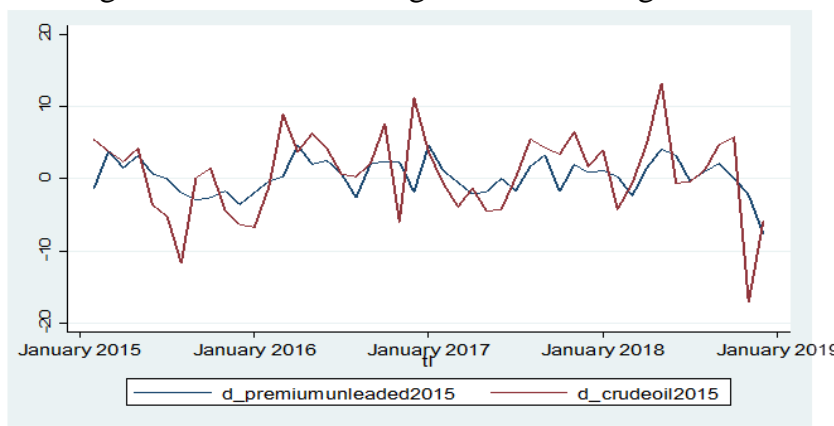

Figure 5: Detrending time series

In order to view AR and MA graphically, the correlogram and partial correlogram plots are viewed respectively. The correlogram is represented in the below figure as ' $A C F$ ' whereas partial correlogram is used to view partial autocorrelations, depicted as 'PACF'.

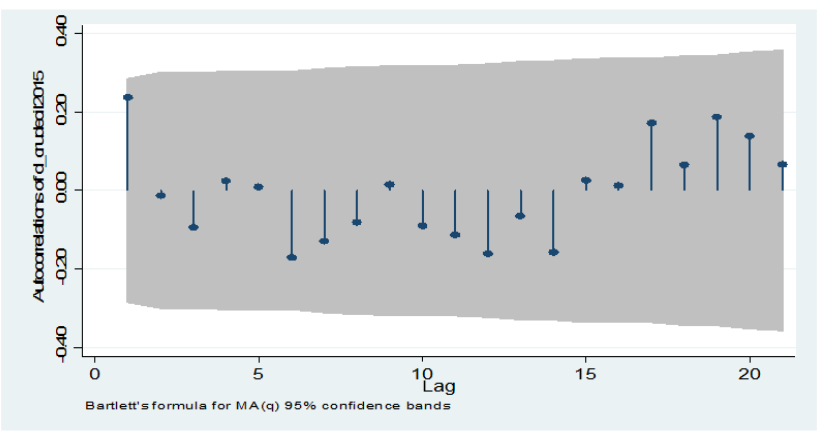

Figure 6: ACF graphs for premium unleaded and crude oil
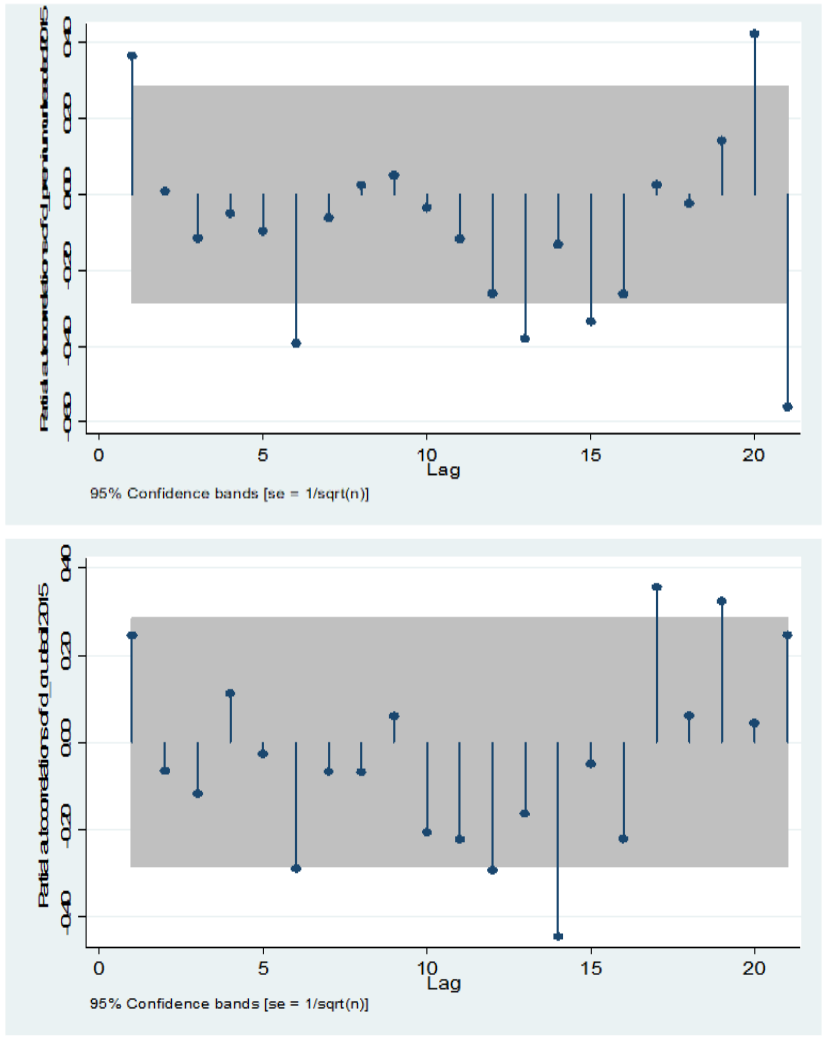

Figure 7: PACF Graph for premium unleaded and crude oil

From the above figures, it can be seen that there are no bars lying outside the grey colored acceptance region. Hence there is no autocorrelation. However, for the partial autocorrelation graph, there are around 4 bars lying outside the acceptance region. Therefore this indicates that there is partial autocorrelation in the data. In consideration of this, the best ARIMA model is identified with maximum significant lags. The final ARIMA model was estimated to be $\operatorname{ARIMA}(0,2,4)$. The table below depicts the regression analysis of crude oil on premium unleaded. Following the best identified ARIMA model, the regression analysis between two times differenced series of both the variables and with four lagged variables turned to be significant. 
Impact of Crude Prices on Retail Prices - A Time Series Analysis

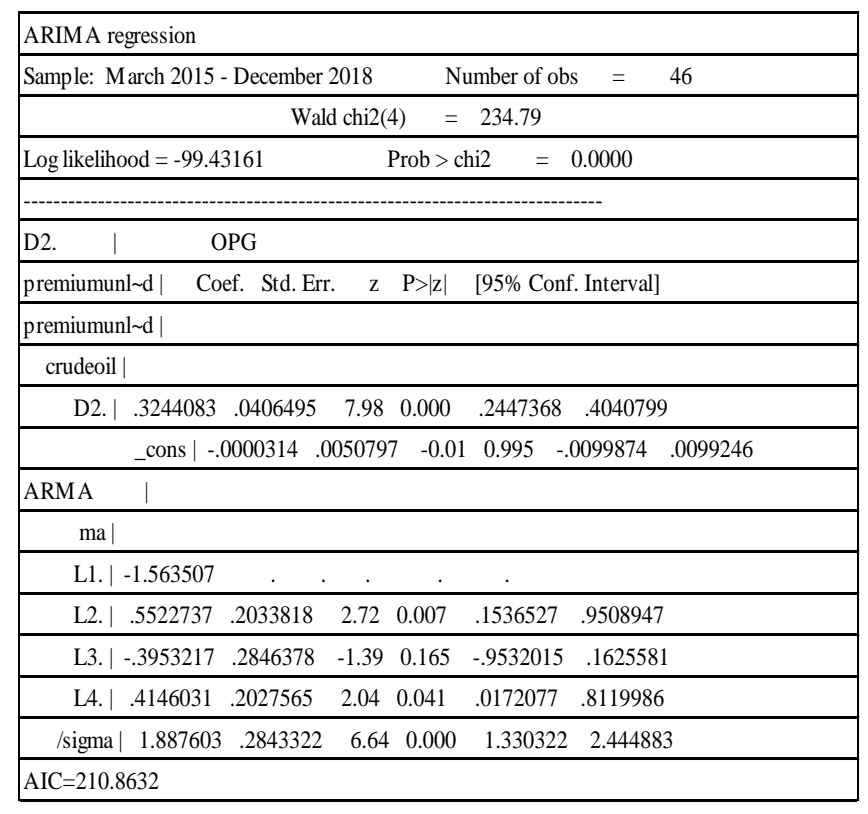

There were two lags significant at $\mathrm{p}$-value being less than 0.05 . Also, the model depicted high log likelihood values and low AIC value in comparison to other attempted ARIMA models. In terms of regression coefficients, crude oil is significant in explaining premium unleaded at $\mathrm{p}<0.05$. The coefficient value indicates that if the price of crude oil changes by one unit, then the price of premium unleaded changes by 0.32 units.

\begin{tabular}{|l|l|}
\hline $\begin{array}{l}\text { Null Hypothesis: There is an } \\
\text { asymmetric association among changes } \\
\text { in price in the retail petrol prices and a } \\
\text { change in price of crude oil }\end{array}$ & $\begin{array}{l}\text { Nojected } \\
\text { Alternate Hypothesis: There is a } \\
\text { symmetric association among changes } \\
\text { in price in the retail petrol prices and a } \\
\text { change in price of crude oil }\end{array}$ \\
\hline
\end{tabular}

\section{COINTEGRATION}

Statistical testing that investigates the relationship between variables for a particular time period such that are non-stationary (Anene, Eloundou, Larach, \& Lugo, 2011). This test aids in depicting that these series turn stationary as well as correlated with respect to time. Also, this testing helps in detecting whether these changes are symmetric overtime or not. Cointegration testing is done using Johansen tests.

The null hypothesis in this context states that there is no co-integration while the alternative hypothesis states that there is cointegration. As discussed above, the time series taken by the researcher was non-stationary, the cointegration test is suitable to be executed.

H0: There is no co-integration between crude oil prices and premium unleaded.

H1: There is co-integration between crude oil prices and premium unleaded.

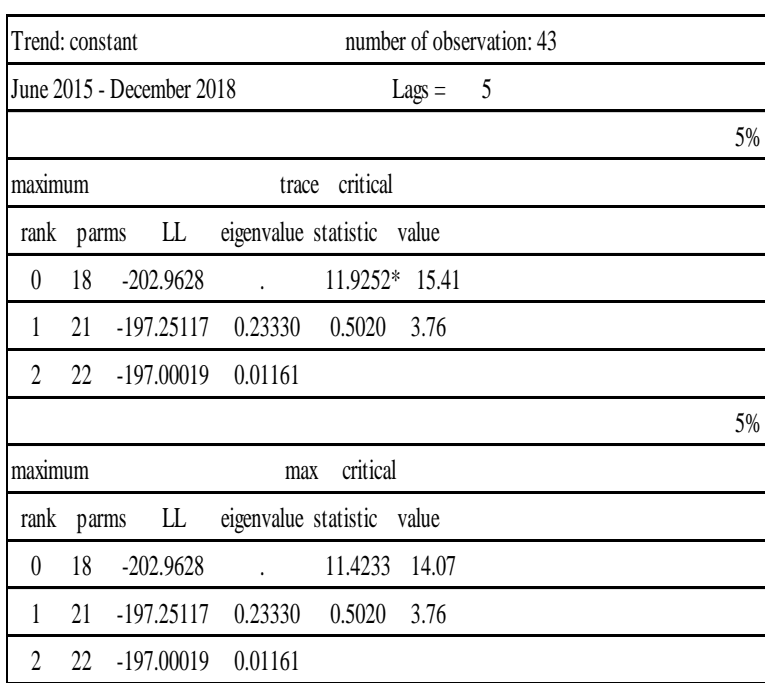

The table above indicates that at zero, there is no cointegration. Since the trace and max statistic are both less than the critical values, the null hypothesis is not rejected. This means that there is no relationship between the variables over a longer period of time. In other words, it can be viewed that there is no symmetric movement of these variables over time. Therefore the main aim of the study is answered with the entire analysis done above. It is evident that there is an asymmetrical movement of prices for both the variables over time.

The result of the main hypothesis is as follows.

\section{CONCLUSION}

The present study examines the relationship between movements of the crude oil prices and retail fuel prices. Overall, it can be said that the relationship between the price moments of crude oil and retail petroleum is asymmetrical. The present study observed the movements of the given variables over a range of time. The results clearly indicated an upward trend among all the series. Hence the series is non-stationary. In order to make the series stationary, the researcher adopted a differencing technique that detrended the series. Following this, the researcher used ARIMA to test the existence of lags. The results indicated that there were lags within the model with respect to the presence of partial autocorrelation. Thus, the ARIMA regression results comprised of differenced and lagged variables that revealed the changes within the independent variables. This indicates that the prices of crude oil significantly impacted retail petrol prices. However, the results indicated through co-integration indicate no co-integration within the variables. This means that the researcher can't reject the null hypothesis. Further, no long-run relationship was observed within the variables i.e. they move in different directions and at different points of time. These results are in consensus with the reviewed literature on this subject.

Although the study conducted covers recent data the results can be generalized only up to an extent. However, the present study limits in

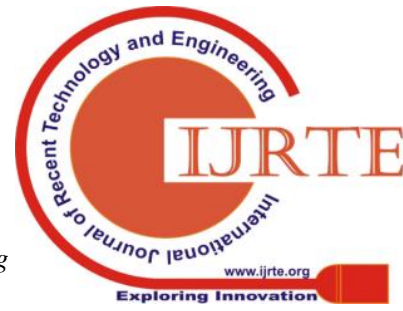


application because the impact was captured for the diminutive period and may not provide the true results in consideration to the aim of the study. Another major limitation of the present study is that the results were framed for a given point of time and may not be useful for future analysis. Hence, the researcher could have adopted the autoregressive distributed lag model (ARDL) and a vector autoregressive (VAR) model for a larger period of time to achieve a more precise and inclusive finding.

In order to achieve better results, the present study should have incorporated additional factors that affect fuel prices. This would assist the researcher in framing a strong relationship between the variables. Furthermore, the results could have covered a long period to capture detailed insights and forecast future trends.

\section{APPENDIX}

Table 1: Autocorrelation test

\section{TABLE 2: AUTOCORRELATION TEST FOR DIFFERENCED VARIABLES}

\section{REFERENCES}

1. Agrawal, A. \&. (2011). An Introductory Study on Time Series Modeling and Forecasting.

2. Anene, B. D., Eloundou, F., Larach, T., \& Lugo, M. (2011) Cointegration of Equity Returns in Brazil, Russia, India, China and South Africa ( BRICS ), 392.

3. Arrow, K. J. (1959). Towards a Theory of Price Adjustment.

4. Atil, A., Lahiani, A., \& Khuong Nguyen, D. (2014). Asymmetric and nonlinear pass-through of crude oil prices to gasoline and natural gas prices. Energy Policy, Elsevier. https://doi.org/10.1016/j.enpol.2013.09.064>

5. Cook, G. (2004). 8 Week Speed Development Program.

6. Cottrell, A. (2004). Economics 215 The Error Correction Model 1 Setting up the EC model. Economics.

7. Deng, C., Jiang, Z., \& Sun, C. (2018). Estimating the efficiency and impacts of petroleum product pricing reforms in China. Sustainability (Switzerland), 10(4), 1-17. https://doi.org/10.3390/su10041080

8. Dias, D. A., Marques, C. R., Martins, F., \& Silva, J. M. C. S. (2009). PRICE ADJUSTMENT LAGS: EVIDENCE FROM FIRM-LEVEL DATA. Winter.

9. Frey, G., \& Manera, M. (2007). ECONOMETRIC MODELS OF ASYMMETRIC PRICE TRANSMISSION. Journal of Economic Surveys, 21(2), 349-415 https://doi.org/10.1111/j.1467-6419.2007.00507.x

10. Gienko, S. (2009). Price Relationships Between Crude Oil And Retail Fuel In Ukraine. Retrieved from http://www.kse.org.ua/uploads/file/SGienko_Thesis2.pdf

11. Helm, T. W. (2012). Essays on the economics of price transmission. The University of Melbourne.

12. Ibrahim, A.-J. (2017). Why the Refineries in the UK perform so poorly? Research Gate.

13. Kanioura, A., \& Turner, P.. "Sheffield Economic Research Paper Series SERP Number" : 2003001, (March)-2003.

14. Karagiannis, S., Panagopoulos, Y., \& Vlamis, P. (2015). “Are unleaded gasoline and diesel price adjustments symmetric? A comparison of the four largest EU retail fuel markets". Economic Modelling, 48, 281-291. https://doi.org/10.1016/J.ECONMOD.2014.11.003

15. Kristoufek, L., \& Lunackova, P. (2014). "Rockets and feathers meet Joseph: Reinvestigating the oil-gasoline asymmetry on the international markets"

16. LANZA, A. (1991). "The speed of Adjustment and Market Structure: A Study of the Gasoline Market in Germany. Oxford Institute for Energy Studies".

17. Lütkepohl, H. (2005). "Vector Error Correction Models. New Introduction to Multiple Time Series Analysis" 237-267. https://doi.org/10.1007/978-3-540-27752-1_6

18. Meyer, J., \& Von Cramon-Taubadel, S. (2002). "Asymmetric Price Transmission: A Survey. EAAE”. Monthly Business Survey. (2016).
Fuel prices explained: A breakdown of the cost of petrol and diesel Office for National Statistics.

19. Noel, D., David, H., \& Cassie, B. (2016). "Petrol and diesel prices", (4712), 25. https://doi.org/SN/SG/4712

20. Perdiguero-García, J. (2013). "Symmetric or asymmetric gasoline prices? A meta-analysis approach";

21. Rosales, F., \& Von-Cramon, S. (n.d.). "Analysis of Price Transmission using a Nonparametric Error Correction Model with Time-Varying Cointegration".

22. Sabnavis, M., Jagasheth, H. U., Khutal, A., \& Kaushik, S. (2017). "Impact of Crude oil price hike. Care Rating", (April), 1-5.

23. Shah, S. R., \& Al-Bargi, A. (2016). "Research Paradigms: Researchers' Worldviews, Theoretical Frameworks, and Study Designs". Awe, 4(4), 252-264. Retrieved from http://www.awej.org/index.php?option=com_content\&view=article\&id= 398:sayyed-rashid-shah-abdullah-al-bargi\&catid=44\&Itemid=133.

24. Silva, A. S. da, Vasconcelos, C. R. F., Vasconcelos, S. P., \& de Mattos, R. S. (2014). "Symmetric transmission of prices in the retail gasoline market in Brazil. Energy Economics", 43, 11-21. https://doi.org/10.1016/J.ENECO.2014.02.002

25. Statista. (2018). "Oil production and consumption in the United Kingdom (UK) | Statista."

26. Waghmare, A. (2018). "Tax on tax gives states a high".

27. Zakaria, M., \& Zakaria, M. (2008). Mp r a, (11543).

28. Zivot, E., \& Wang, J. (2006). "Unit Root Tests. Modeling Financial Time Series with S-PLUS", (1), 111-139. https://doi.org/10.1016/0304-4076(92)90104-Y

29. Zlatcu, I., Kubinschi, M., \& Barnea, D. (2015). "Fuel Price Volatility and Asymmetric Transmission of Crude Oil Price Changes to Fuel Prices. Theoretical and Applied Economics", XXII(4), 33-44.

\section{AUTHORS PROFILE}

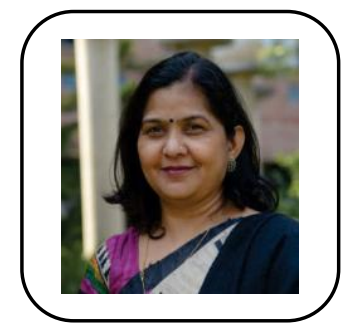

Dr. Neelu Tiwari is working as Associate Professor at Jaipuria Institute of Management,Ghaziabad, India. Her research area is Business Statistics and Operations Research. She has 17 years of Teaching and 04 years of research experience. She has $27 \mathrm{~b}$ esearch papers published and presented in various national/international journal and conferences. She has authored 4 books on statistics and operation research. She has received award in business analytics for management decision from IIT Kharagpur. 